\title{
Investigation of energy transport and thermospheric upwelling during quiet magnetospheric and ionospheric conditions from the studies of low- and middle-altitude cusp
}

\author{
T. Živković ${ }^{1,3}$, S. Buchert ${ }^{1}$, P. Ritter ${ }^{2}$, L. Palin ${ }^{1}$, and H. Opgenoorth ${ }^{1}$ \\ ${ }^{1}$ Swedish Institute of Space Physics, University of Uppsala, Sweden \\ ${ }^{2}$ Deutsches GeoForschungsZentrum, GFZ, Telegrafenberg, 14473 Potsdam, Germany \\ ${ }^{3}$ Research and Innovation, DNV GL, Høvik, Norway
}

Correspondence to: T. Živković (tatjana.zivkovic.hansen@dnvgl.com)

Received: 22 April 2014 - Revised: 28 April 2015 - Accepted: 30 April 2015 - Published: 1 June 2015

\begin{abstract}
We investigate energy fluxes and small, kilometrescale Birkeland currents in the magnetospheric cusp at a 13 Earth radii altitude and in the ionosphere using satellites when they were, according to the Tsyganenko model, in magnetic conjunction within $50-60 \mathrm{~km}$ and up to $15 \mathrm{~min}$ apart. We use Cluster and CHAMP satellites, and study three conjunction events that occurred in 2008 and 2009, when the Cluster spacecraft were crossing the cusps at only a few Earth radii altitude. Our goal is to understand better the influence of processes in the magnetospheric cusp on the upper thermosphere and its upwelling which was usually observed by the CHAMP satellite passing the cusp. Three studied events occurred under relatively quiet and steady magnetospheric and ionospheric conditions, which explains why observed thermospheric density enhancements were rather low. Our findings point out that for each studied event soft electron precipitation influences thermospheric density enhancements in a way that stronger electron precipitation produces stronger thermospheric upwelling. Therefore, in the case of these weak events, soft electron precipitation seems to be more important cause of the observed, thermospheric density enhancements than is the Joule heating.
\end{abstract}

Keywords. Magnetospheric physics (energetic particles precipitating)

\section{Introduction}

The interaction between the near-Earth space and the ionosphere involves field-aligned currents (FACs) as first envis- aged by Birkeland (1913). The relatively large-scale FAC systems of the nightside aurora have been studied and analysed extensively, see for example, a review by Baumjohann (1982). The appearance of optical aurora often suggests also the presence of small-scale, less than a kilometre wide FACs. These have indeed been found with the help of sufficiently rapidly sampling magnetometers on board satellites in low orbits - for example, see Dahlgren et al. (2011). The Ørstedt and CHAMP satellites, launched in 1999 and 2001, respectively, featured high-precision and fast sampling (10 and $50 \mathrm{~Hz}$ ) fluxgate magnetometers as well as polar orbits. Perhaps surprisingly, the most intense FACs were found with these satellites not in the nightside auroral zone, but on the dayside in the cusps, reaching a few hundred $\mu \mathrm{Am}^{-2}$ and with scales down to a few hundred metres (Neubert and Christiansen, 2003; Watermann et al., 2003). Particularly, it was shown by Neubert and Christiansen (2003), who used Ørsted, that small-scale FACs were 1-2 orders of magnitude larger than large-scale Region 1 and 2 currents.

CHAMP was a German mission, which was flying in the altitude between $300-450 \mathrm{~km}$ with an inclination of $87.3^{\circ}$. Besides the Earth's magnetic field, CHAMP was designed to map the Earth's gravity field and carried also an accelerometer, and was accurately tracked with GPS and satellite laser ranging. This allowed accurate determination of the satellite's air drag.

Lühr et al. (2004) showed that air drag plots from CHAMP had one dominant oscillation which was due to the air density difference on the day and night side of the Earth. Superimposed on this oscillation were relatively narrow peaks 
in air drag corresponding to widths of a few tens to hundred kilometres of enhanced neutral density. These thermospheric upwellings seemed to occur in the cusps and were accompanied by intense kilometre-scale FACs, which were probably causing the upwellings.

One obvious question that deserves attention is whether FACs in the cusp are the cause for thermospheric upwelling, or if other mechanisms can also influence it. This paper tries to address this question.

Watermann et al. (2008) used, in addition to magnetometer measurements of Ørsted and CHAMP, particle data from the low-orbiting DMSP satellites. They showed that cusp locations as inferred from magnetosheath-like particle precipitation matched well the locations of small-scale currents, but FACs seem to be generated also in the transition zone between the low-latitude boundary layer (LLBL) and the cusp. Small-scale intense FACs could also, with the help of the DMSP F15 ion drift and magnetometer, be associated with very strong enhancements of the Poynting flux ( $\mathrm{Li}$ et al., 2011). These authors proposed that magnetic reconnection in the cusp, particularly during a large $B_{y}$ component and northward $B_{z}$, is a cause of such small-scale, but intense Poynting flux increases.

The four ESA Cluster satellites were launched in 2001 with an initial perigee at $26000 \mathrm{~km}$ (4RE) and apogee at $124000 \mathrm{~km}$ (19RE) with orbits that relatively frequently crossed the cusps at varying altitudes. We use magnetic field data from the Cluster fluxgate magnetometer (FGM) instrument (Balogh et al., 2001), electric field data from the EFW instrument (Gustafsson et al., 2001), spin resolution electron spectrograms from the LEEA sensor on the Plasma Electron and Current Experiment (PEACE) (Johnstone et al., 1997), as well as ion spectrograms of the precipitating particles from the HIA and CODIF censors of the Cluster Ion Spectrometer (CIS) instrument (Rème et al., 2001).

Studies of energy deposition in the cusp were conducted by Yordanova et al. (2007), when Cluster was in conjunction with the EISCAT Svalbard radar and the MIRACLE network. However, that study was for the exterior cusp, when Cluster was at around $9 R_{\mathrm{E}}$ and no localized current sheets were estimated at Cluster or lower altitudes. The conclusion from that paper was that particle fluxes seen by Cluster in the exterior cusp were enough to heat the $F$ layer, while the Poynting flux was more than enough to account for the Joule heating in the $E$ ionospheric layer. Also, Chaston et al. (2005) studied a conjunction between Cluster and FAST satellite, and a conclusion was, after a comparison of the Poynting and particle fluxes, that the energy deposition to the dayside auroral oval was due to field-aligned electron acceleration, transverse ion-acceleration, and Joule heating.

In this paper, we are particularly interested in cases where the Cluster spacecraft are located at midaltitudes (a few $\mathrm{R}_{e}$ ) in the interior cusp, and where chances to find FAC sheets extending over large distances from the ionosphere into near
Earth space are greater than when Cluster is located further away in the exterior cusp.

We use the Cluster spacecraft and the CHAMP satellite to investigate whether the continuation of ionospheric smallscale current sheets can be found at much higher altitudes of a few Earth radii. In addition, we compute field-aligned particle energy and Poynting fluxes at Cluster, as well as the Joule heating in the ionosphere, in order to quantify the importance of each of these mechanisms for the thermospheric density enhancements. Our method of investigation is based on conjunctions between Cluster and CHAMP satellites, which passed the same area within less than $15 \mathrm{~min}$. We are aware that electrodynamics measured by Cluster are much more transient in nature than the thermospheric density enhancements which are an integrated effect in the thermosphere (Whitteker, 1977). On the other hand, we can safely assume that the processes in the cusp which are observed by the spacecraft used in this study have been active for quite a while before the actual spacecraft encountered. We have carefully chosen events which had quiet and relatively steady IMF conditions as well as low $\mathrm{AE}$ and $K_{\mathrm{p}}$ indices several hours prior to studied time intervals, such that the studied thermospheric upwellings can be considered to be a consequence of the cusp precipitation measured by Cluster in the conjunction. We also note that there were only three events within 21 conjunctions which showed field-aligned current activity at all (see below) and thus the events may not be entirely ideal in all relevant parameters. It is by definition very difficult to find conjunctions between two spacecraft over the right active region in space and time.

Similar study was done by Sadler et al. (2012) who studied a conjunction between FAST and CHAMP satellite. Their conclusion was that thermospheric density enhancements were a combination of soft particle precipitation and ion outflow, which further, drove neutrals to the CHAMP altitude.

\section{Computation of currents, particle and Poynting flux and Joule heating}

There are two ways to determine parallel current density from the Cluster spacecraft. It is by magnetic field (FGM) instrument and by CIS and PEACE particle instruments. In this paper, the field-parallel current density is determined from the Cluster magnetic field instrument (FGM) which provides the temporal variations of the magnetic field $\boldsymbol{B}$ in the spacecraft frame. The spatial structure of $\boldsymbol{B}$ in Geocentric Solar Ecliptic (GSE) coordinates is derived using the plasma velocity vector from the ion instrument (CIS) and the known satellite velocity at this particular portion of the orbit. The Cluster satellites were too far apart to use intersatellite correlation or a curlometer method. Further, we use Ampere's law $\nabla \times \boldsymbol{B}=\mu_{0} \boldsymbol{j}$ in a finite difference approximation: $\mu_{0} \boldsymbol{j}=\boldsymbol{v} /\left(|\boldsymbol{v}|^{2} \mathrm{~d} t\right) \times d \boldsymbol{B}$. The FAC density is then $\boldsymbol{j} \times \boldsymbol{B} /|\boldsymbol{B}|$. Here $\mathrm{d} \boldsymbol{B}$ is the difference of the magnetic field vector over 
the sampling interval $\mathrm{d} t$, which is about $1 /(22 \mathrm{~Hz}), v$ is then the plasma velocity from CIS instrument plus the satellite velocity, both in GSE coordinates. We assume that the current sheet is frozen into the plasma. We also compute total electron downgoing energy fluxes (EEF) from the PEACE Cluster instruments. PEACE gives differential particle fluxes as a function of 12 pitch angle bins and 44 energy bins. Further, we estimate the energy flux from the particles in the loss cone.

In order to estimate the relative importance of the fieldaligned electromagnetic energy flux compared to the particle energy fluxes at Cluster, we also show the Poynting flux $\boldsymbol{E}_{\text {perp }} \times \mathrm{d} \boldsymbol{B} / \mu_{0}$ obtained from the electric field perpendicular to $\boldsymbol{B}, \boldsymbol{E}_{\text {perp }}$, and the deviation of the $\boldsymbol{B}$ from a background, $\mathrm{d} \boldsymbol{B}$. A polynomial fit to the total $\boldsymbol{B}$ from the FGM instrument is used to estimate the background $\boldsymbol{B}$.

Poynting flux extrapolated to the ionosphere is obtained from $P_{\mathrm{i}}=P_{\mathrm{cl}} B_{\mathrm{i}} / B_{\mathrm{cl}}$, where $B_{\mathrm{cl}}$ and $P_{\mathrm{cl}}$ are magnetic field and Poynting flux computed at Cluster, while $B_{\mathrm{i}}=50000 \mathrm{nT}$.

The level 1 fluxgate magnetometer data from CHAMP have a time resolution of $50 \mathrm{~Hz}$ with a nominal amplitude resolution of $0.1 \mathrm{nT}$. The FAC density in the ionosphere is estimated along the satellite track from the magnetic field component perpendicular to the auroral oval, assuming stationary sheet currents (Wang et al., 2005). Positive currents flow upward. Assuming that FAC sheets do not close between the ionosphere and Cluster altitude and that there are no intermittent disturbances like FAC carrying Alfvén waves, the field-aligned current density in the ionosphere $j_{\mathrm{i}}$ should be approximately $\left(B_{\mathrm{i}} / B_{\mathrm{cl}}\right) j_{\mathrm{cl}}$, where $B_{\mathrm{i}}$ is the magnetic field at ionospheric altitude, $B_{\mathrm{cl}}$ is the mean magnetic field at Cluster and $j_{\mathrm{cl}}$ is the estimated current density at Cluster. Neutral density measurements in the thermosphere are obtained from the recently calibrated accelerometer data set from CHAMP (Doornbos et al., 2010). The density is projected to the CHAMP altitude $h_{\mathrm{c}}$ as $\rho\left(h_{\mathrm{c}}\right)=\rho(h) \times \rho_{\mathrm{m}}\left(h_{\mathrm{c}}\right) / \rho_{\mathrm{m}}(h)$. Here, $\rho_{\mathrm{m}}(h)$ is the model mass density according to the NRLMSISE-00 atmospheric model (Picone et al., 2002) at the satellite altitude, while $\rho$ is the measured mass density at the same altitude.

Joule heating $W_{\mathrm{J}}$ is caused by the dissipative Pedersen currents which close FACs mainly in the $E$ region. The usual formula $W_{\mathrm{p}}=\Sigma_{\mathrm{p}} \boldsymbol{E}_{\text {perp }}^{2}$, where $\Sigma_{\mathrm{p}}$ is the height-integrated Pedersen conductivity, cannot be directly used here, because CHAMP provides only B, not $\boldsymbol{E}_{\text {perp. Previously Sugiura }}$ (1984) has shown, using DE-2 satellite where both $\boldsymbol{B}$ and $\boldsymbol{E}_{\text {perp }}$ were measured, that $\boldsymbol{E}_{\text {perp }}$ and $\delta$ B are highly correlated at FAC structures, and that $\boldsymbol{E}_{\text {perp }} / \delta \boldsymbol{B} \sim 1 /\left(\mu_{0} \Sigma_{\mathrm{p}}\right)$. This can also be derived theoretically by equating the Joule heating with the Poynting flux $\boldsymbol{E}_{\text {perp }} \times \delta \boldsymbol{B} / \mu_{0}$ (Kelly, 2012, p. 270). Inserting the formula for $\boldsymbol{E}_{\text {perp }} / \delta \boldsymbol{B}$ into the Joule heating formula, we get $W_{\mathrm{j}} \sim(\delta \boldsymbol{B})^{2} /\left(\mu_{0} \Sigma_{\mathrm{p}}\right)$.

$\Sigma_{\mathrm{p}}$ depends on the electron density $N_{\mathrm{e}}$ and on neutral atmospheric density. We compute $N_{\mathrm{e}}$ using the IRI model (http://omniweb.gsfc.nasa.gov/vitmo/iri_vitmo.html), while molecular and atomic oxygen, nitrogen and helium densities are obtained using the MSISE90 model (http://omniweb. gsfc.nasa.gov/vitmo/msis_vitmo.html) introduced by Hedin (1991). Standard expressions for the ion-neutral collisional cross-section (Schunk and Nagy, 2004) were then used to calculate $\sigma_{\mathrm{p}}$ and integrate it over heights from 90 to $180 \mathrm{~km}$ to obtain $\Sigma_{\mathrm{p}}$. Model outputs are computed for geographic latitude, longitude and time when CHAMP currents were observed.

In the analysis of the studied events, we compare average fluctuations of the Poynting flux, average fluctuations of the current density and average fluctuations of the EEF at Cluster to the same quantities in the ionosphere. Here, by average fluctuations we mean standard deviation of the respective data.

\section{Results}

It has been shown by Carlson et al. (2012) that strong plasma flow channels in the cusp can last for $\sim 15-20 \mathrm{~min}$, can be $100 \mathrm{~km}$ wide, more than $1000 \mathrm{~km}$ long and are found within $\sim 5 \mathrm{~h}$ of MLT noon. We have followed these criteria when we searched for conjunctions between Cluster and CHAMP in years 2008 and 2009. These years were selected since Cluster was passing the cusp at low and middle altitudes in that period. For our event selection, Cluster and CHAMP had to be less than $15 \mathrm{~min}$ apart in their relative passage of the cusp. Geographic latitudes of the mapped Cluster footpoint and CHAMP were about $0.5^{\circ}$ apart due to uncertainty in the Tsyganenko model, while the difference between the geographic longitudes had to be at most $20^{\circ}$, due to current elongation (Carlson et al., 2012). Of particular interest were the conjunctions that occurred at mid altitudes, when Cluster satellites were at about $1-3 R_{\mathrm{E}}$.

In order to compute Cluster footprints we used the Orbit Visualization Tool (OVT), which uses the Tsyganenko 96 model (Tsyganenko and Stern, 1996) for the field line tracing. OVT is described and can be downloaded from http: //ovt.irfu.se. The Cluster footprints are computed for an altitude of $120 \mathrm{~km}$ above the Earth, with 1 min time resolution. The CHAMP spacecraft's circular orbit was at about $340 \mathrm{~km}$ altitude, and its orbital velocity was $v_{s}=7.7 \mathrm{~km} \mathrm{~s}^{-1}$. Using our criteria, we have detected 11 conjunctions between Cluster C3 and CHAMP in the cusp, at midaltitudes in 2008 and 10 conjunctions in 2009 , but only three out of these 21 identified conjunctions exhibited regions or bundles of structured field-aligned currents (explained in more detail later), and were thus chosen for this particular study. All others revealed no such feature and consequently also no thermospheric density increases were observed (which is a finding in itself - see Conclusions section below).

The CHAMP fluxgate magnetometer data were used to estimate current densities. Neutral density estimates were obtained from the TU Delft thermosphere web server (http: 


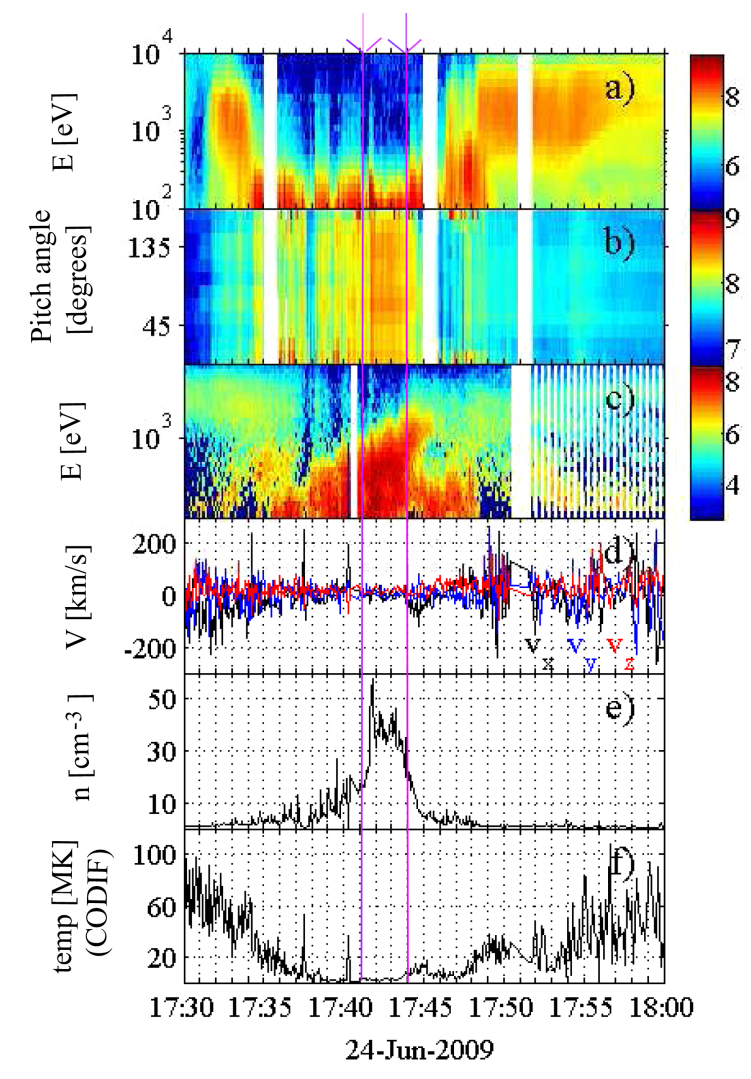

Figure 1. Cluster 4 on 24 June 2009: (a) electron spectrogram, (b) pitch angle distribution of electrons, (c) ion spectrogram, (d) ion velocity in GSE, (e) ion density, (f) parallel (to mag. field) temperature. Two violet lines mark the cusp extension.

//thermosphere.tudelft.nl/acceldrag/index.php). The processing is described in Doornbos et al. (2010). Here we analyse three conjunctions that revealed bundles of FAC on both Cluster and CHAMP satellites, on 24 June 2009, 17 July 2008 and 9 June 2008. All three events had very quiet interplanetary magnetic field and solar wind conditions, but we note that there was some activity preceding event 2 . However, in that case the nightside activity was declining, and thus corresponding cusp activity must have disappeared much earlier already. According to Schlegel et al. (2005) who studied cusp by CHAMP satellite, thermospheric density enhancements during quiet conditions were mainly observed between 09:00 and 15:00 MLT. All three conjunctions occurred in this MLT range.

\subsection{June 2009 cusp event}

For this event, the OMNI database showed that the interplanetary magnetic field (IMF) was not changing and was rather low: $B_{x}$ was at about $7 \mathrm{nT}, B_{y}$ was around $0 \mathrm{nT}$, while $B_{z}$ was slightly below $0 \mathrm{nT}$. The $K_{\mathrm{p}}$ index was at about 2 in the period of several hours before this conjunction event, while the $\mathrm{AE}$ index stayed less than $100 \mathrm{nT}$ in the same pe- riod. The solar wind dynamic pressure was high and stayed at about $\sim 8 \mathrm{nPa}$. A comparison between magnetic field at Cluster 3 and the Tsyganenko 96 prediction for the magnetic field showed alignment among each of the components (here not shown). That demonstrated that constant solar wind IMF allows very accurate prediction of the Tsyganenko 96 model, even if solar wind, dynamic pressure was high. Cluster 3 was at $2.08 R_{\mathrm{E}}$ in the time of the conjunction. Cluster 4 was at $2.14 R_{\mathrm{E}}$, about $650 \mathrm{~km}$ apart. Figure 1 shows for the period of 17:30 to 18:00 UT electron and ion characteristics as measured from the PEACE and CIS instruments at the Cluster 4. Perpendicular temperature has the same profile as parallel temperature and is, hence, not shown. According to Fig. 1, cusp precipitation is seen from around 17:40 to 17:44 at Cluster 4 . For the same time period, the cusp is also identified at Cluster 3. Generally, Cluster 3 and Cluster 4 give the same results for all studied parameters in this time interval. Here, results for the Cluster 4 are presented, but CIS CODIF is used for ion velocity, density and temperature, since CIS HIA was not available for the Cluster 4 spacecraft. Before and after cusp passage in Fig. 1, electron energies from the spectrogram correspond to the low-latitude boundary layer values. We note from the velocity data in panel (d) that there is neither a sunward nor antisunward flow channel associated with this cusp crossing, in spite of all other parameters being typical for the cusp. However, we like to point out that the flow channel is a signature of an active cusp, i.e. immediately ongoing reconnection. As reconnection occurs in bursts not all cusp crossings must exhibit a flow channel in the ionosphere, even if typical cusp particles keep on precipitating from the (reasonably) newly reconnected field lines, carrying the FAC current bundle. Because of this, we continue using 'bundle of FAC' when we address current density fluctuations on Cluster and CHAMP.

In Fig. 2 we show satellite's passages in geographical coordinates. Magnetic latitude (MLAT) and magnetic local time (MLT) are written for satellite's positions in the conjunction. The best conjunction occurred when Cluster 3 had MLAT 77.42, MLT 9.25, Cluster 4 had MLAT 78.43, MLT 9.78 and CHAMP had MLAT 78.31, MLT 9.31. In Fig. 3, intensifications in the parallel (field-aligned) Poynting flux, parallel current density and the Earthward EEF can be observed in the period of cusp intersection. Positive Poynting flux is towards the Earth. The average fluctuation of the parallel Earthward Poynting flux through the cusp passage lasting between 17:40 and 17:44 UT, is $0.39 \mathrm{~mW} \mathrm{~m}^{-2}$. The average current sheet density fluctuation for the same time interval is about $0.6 \mu \mathrm{A} \mathrm{m}^{-2}$. The average fluctuation of the Earthward EEF is $0.13 \mathrm{~mW} \mathrm{~m}^{-2}$, which gives $2.16 \mathrm{~mW} \mathrm{~m}^{-2}$ when projected to the thermosphere (see red scale in lowest panel). The same results are obtained by both Cluster 3 and Cluster 4. The period of conjunction was also the period when currents were intensified at CHAMP as can be envisaged from Fig. 4a. For the mean magnetic field at Cluster during the conjunction of $B_{\mathrm{cl}} \sim 3 \mu \mathrm{T}$, the ionospheric FAC 


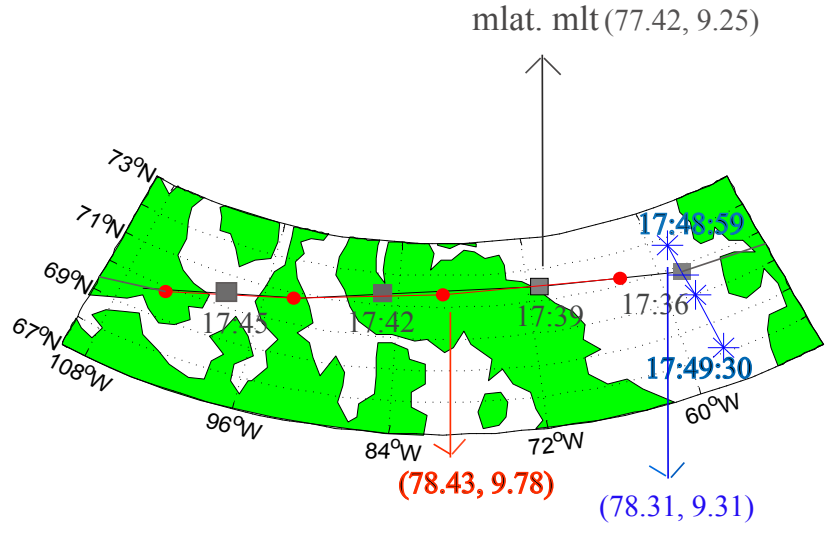

Figure 2. Projection of satellite footprints to $120 \mathrm{~km}$ altitude in geographical coordinates for 24 June 2009: red dots are for Cluster 4, grey squares are for Cluster 3, blue stars are for CHAMP. Times in blue are for the CHAMP, while grey times are for Cluster 3. Arrows point to magnetic latitude and magnetic local time for satellites in conjunction.

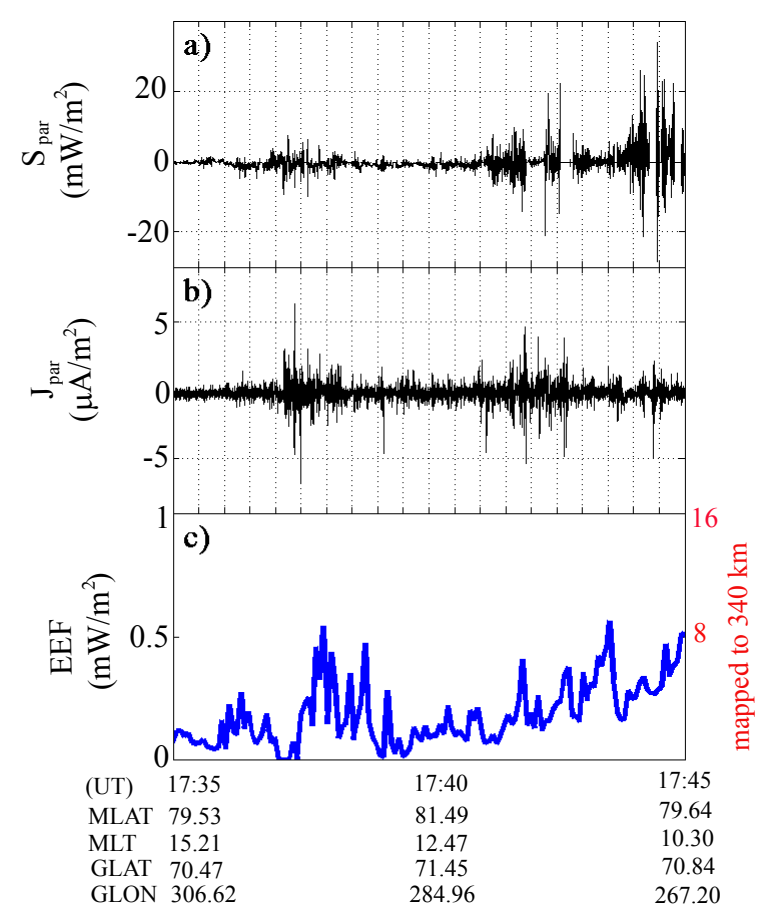

Figure 3. Cluster 4 on 24 June 2009: (a) parallel Poynting flux, (b) parallel current density and (c) electron energy fluxes, where blue colour indicates Earthward direction. Right axis shows EEF mapped to troposphere.

density average fluctuations should be about 16 times higher than the current density average fluctuations computed at Cluster according to the ionospheric current density estimate from Sect. 2. That would give average ionospheric current density fluctuations of $9 \mu \mathrm{A} \mathrm{m}^{-2}$. From the data at CHAMP, the average current density fluctuations are about $18 \mu \mathrm{A} \mathrm{m}^{-2}$,
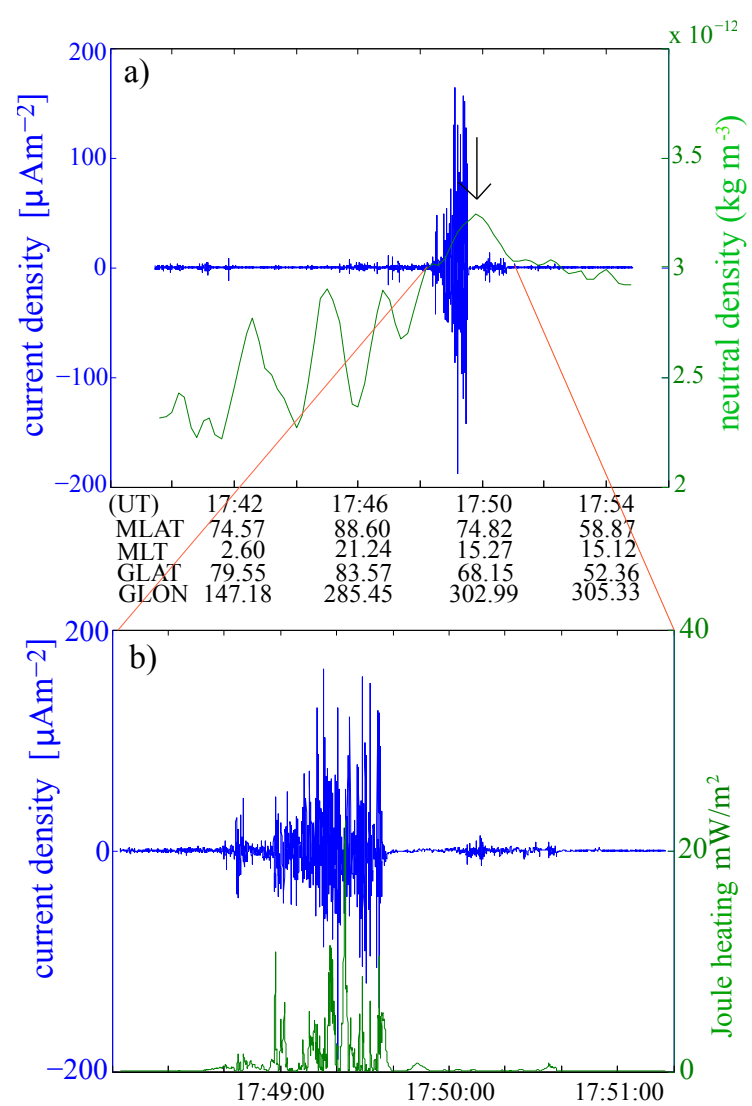

Figure 4. (a) CHAMP current and neutral density for 24 June 2009. (b) Estimated Joule heating for the $E$ layer on 24 June 2009, with the CHAMP current density on the top.

which is 2 times higher than expected from estimated Cluster current density fluctuations. Still, considering our rough estimates, we assume that we see the same bundle or region of FAC on both Cluster and CHAMP spacecraft in the conjunction period. The corresponding thermospheric upwelling observed from the CHAMP accelerometer data goes up to $\sim 3.2 \times 10^{-12} \mathrm{~kg} \mathrm{~m}^{-3}$, as can be seen in Fig. 4a, which is about $20 \%$ more than the above background. This upwelling is significant as is evidenced by mean and standard deviation of the air neutral density as reported in Table 1 (see below). From Fig. 4b, average Joule heating fluctuation for the $E$ region is $2.88 \mathrm{~mW} \mathrm{~m}^{-2}$. The projected Earthward Poynting flux fluctuation is $6.50 \mathrm{~mW} \mathrm{~m}^{-2}$, which shows that Poynting flux is about 2.25 times stronger than the Joule heating for the $E$ layer.

From the CIS CODIF instrument at Cluster, we measure density and velocity along the magnetic field for the oxygen ions. Figure 5 shows oxygen density and parallel velocity from Cluster 4 . Negative velocity indicates oxygen ions coming from the ionosphere. We see densities up to $4 \mathrm{~cm}^{-3}$ together with velocities up to $20 \mathrm{~km} \mathrm{~s}^{-1}$ in the period before 17:42 UT. Oxygen ions coming from the ionosphere could be a result of both Joule heating from the $E$ region, but also 


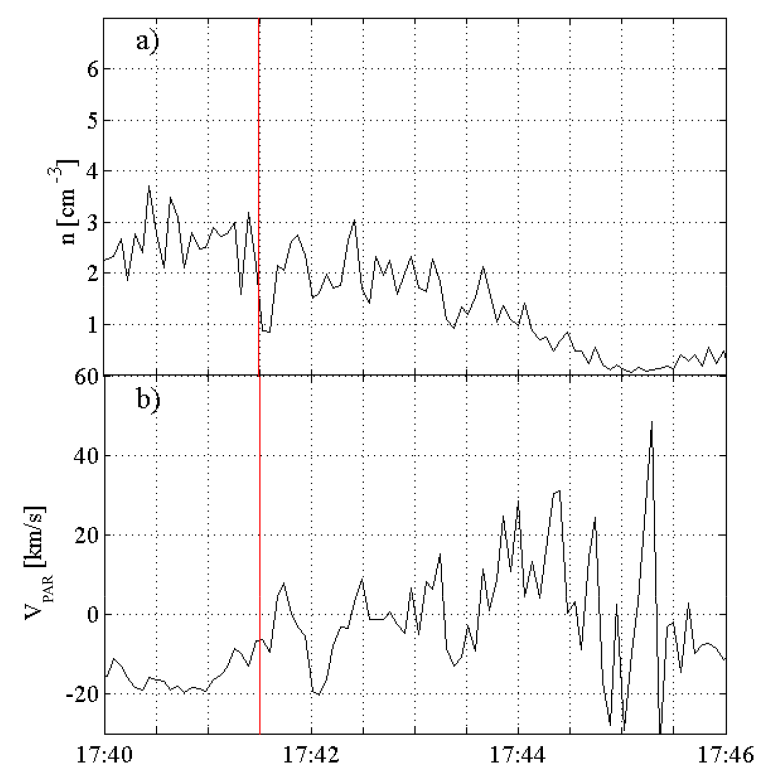

Figure 5. Cluster 4 oxygen on 24 June 2009: (a) density, (b) GSE velocity along the magnetic field; red line indicates the end of area where oxygen ions travel from the ionosphere.

from the charge imbalance produced through soft electron precipitation (Sadler et al., 2012).

\subsection{July 2008 cusp/magnetopause event}

During this event, the OMNI database shows that the interplanetary magnetic field (IMF) for the period of conjunction was relatively quiet: $B_{x}$ was varying between -1 and $1 \mathrm{nT}, B_{y}$ was negative all the time varying between $-2.2 \mathrm{nT}$ and $-0.3 \mathrm{nT}$, while $B_{z}$ was slightly negative just before the actual cusp encounter, varying around $\sim-1.5 \mathrm{nT}$. It became positive after 03:25 UT reaching a maximum value of $0.7 \mathrm{nT}$. The $K_{\mathrm{p}}$ index was less than 3 in the period of several hours before this conjunction event, while the $\mathrm{AE}$ index decreased from about 250 to $150 \mathrm{nT}$ in the same period. In addition, the solar wind dynamic pressure was at about $\sim 1.3 \mathrm{nPa}$. From Fig. 6. one can conclude that the cusp was observed from 03:34 to 03:37. In the cusp duration, we see in Fig. 6a electron energies up to $1 \mathrm{keV}$ with fluxes up to $10^{8} \mathrm{eV} \mathrm{cm}^{-2} \mathrm{~s}^{-1} \mathrm{sr}^{-1} \mathrm{eV}^{-1}$. In Fig. 6c ion spectrograms are shown. High fluxes of $\sim \mathrm{keV}$ ions for the interval 03:3403:37 indicate a magnetosheath-like population, typical for the cusp. In the same figure, a reversed ion dispersion can be seen from 03:37 to 03:40. The ion dispersion is consistent with the IMF measurements. Namely, since IMF $B_{z}$ is positive in this period, while IMF $B_{x}$ and $B_{y}$ are small, a reconnection might have occurred in the lobes, poleward of the cusp (Pitout et al., 2012). The convection of the magnetic field lines is then sunward and ion energy decreases with decreasing latitude which causes a reverse ion dispersion. This is consistent with ion velocity measurements on

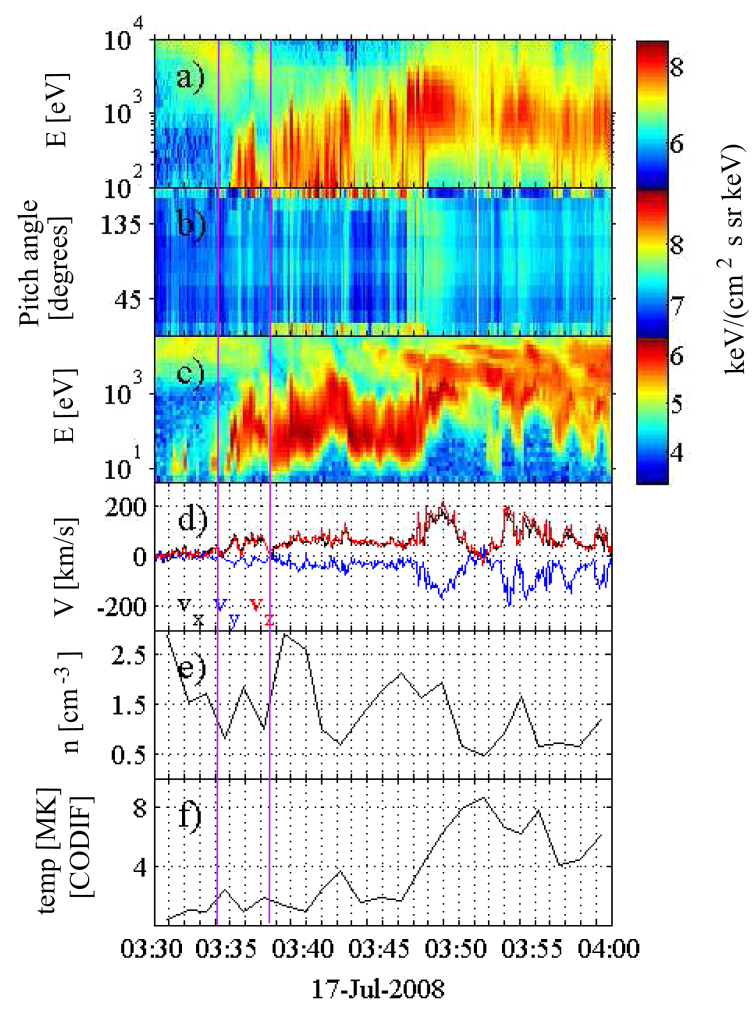

Figure 6. Cluster 3 on 17 July 2008: (a) electron spectrogram, (b) pitch angle distribution of electrons, (c) ion spectrogram, (d) ion velocity in GSE, (e) ion density, (f) parallel (to mag. field) temperature. Two violet lines mark the cusp extension.

HIA instrument on CIS (Fig. 6d), where positive $V_{x}$ (here in black colour) confirms that magnetic field lines, indeed, convect sunward as predicted for such a situation. After 03:37 both upward and downward electron fluxes indicate the magnetopause with closed field lines.

The Tsyganenko 96 model predicted that the Cluster 3 would be on open field lines from 03:20 to 03:40 UT (here not shown). The closest other Cluster 1 arrived at the same area of the inner cusp $30 \mathrm{~min}$ earlier and, hence, could not be used for our study. However, we have inspected Cluster 1 data when it was in the cusp, but no strong particle precipitation could be detected for that interval.

In order to get as precise Cluster footprints as possible, we have used the solar wind IMF, dynamic pressure and $D_{s t}$ index starting 2 hours before the event, as the input parameters to the Tsyganenko 96 model. Figure 7 shows the magnetic field at Cluster 3 and the one predicted from the Tsyganenko model at the altitude of Cluster, both in GSE coordinates. Apart from some disagreement in the $B_{y}$ component, the Tsyganenko model gives a very good description of the magnetic field at Cluster. Figure 8 summarizes passages in geographical coordinates of the Cluster 3 and CHAMP satellite. Footprints in the conjunction for Cluster 3 are MLAT 77.03, MLT 10.65 and for CHAMP are MLAT 76.66, MLT 


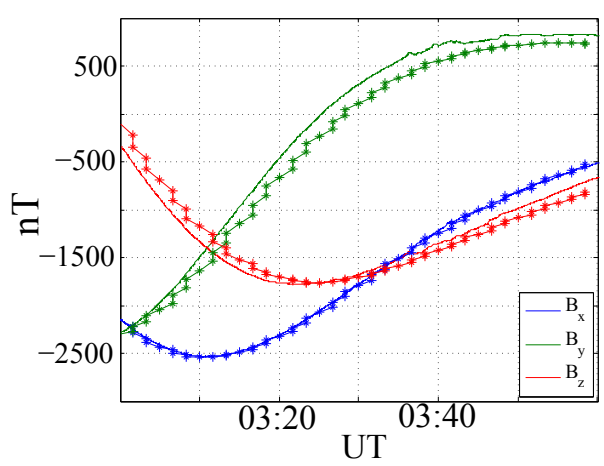

Figure 7. Magnetic field in GSE coordinates from Tsyganenko model (stars) and Cluster 3 FGM instrument, for 17 July 2008.

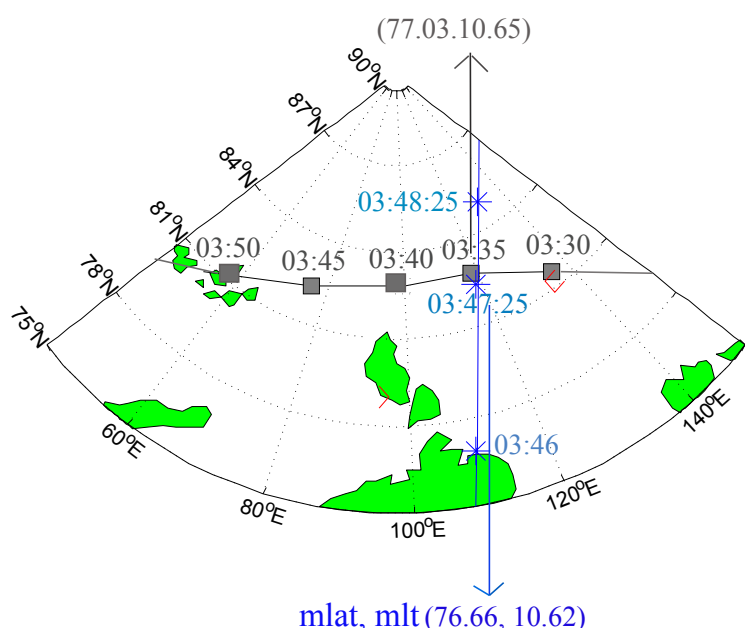

Figure 8. Satellite footprints in geographical coordinates for 17 July 2008: blue star is for CHAMP, grey squares are for Cluster 3. Colours of times in the plot correspond to the colours of satellite's footprints. Arrows point to magnetic latitude and magnetic local time for satellites in conjunction.

10.62. The closest conjunction occurred for the time period when Cluster 3 was still in the cusp at 03:35 UT. Figure 9a shows Cluster 3 parallel, Poynting flux in the time interval between 03:30 to 03:45. The average fluctuation of the parallel Earthward Poynting flux during cusp passage between 03:34 and 03:37 UT is $0.49 \mathrm{~mW} \mathrm{~m}^{-2}$. In Fig. 9b a Cluster 3 current density is estimated. Here, we see current sheets starting from 03:36, where average current density fluctuation during cusp interval is $0.2 \mu \mathrm{A} \mathrm{m}^{-2}$. Further, EEF is estimated in Fig. 9c. This flux is considerably weaker than the EEF for the first event. The average fluctuation for the Earthward EEF is only $0.04 \mathrm{~mW} \mathrm{~m}^{-2}$, whose extrapolated, thermospheric value is $1 \mathrm{~mW} \mathrm{~m}^{-2}$.

The estimated FAC density on CHAMP is shown in Fig. 10a. The average current density fluctuation is $5.48 \mu \mathrm{A} \mathrm{m}^{-2}$. Further, we can estimate how well the current density fluctuation at CHAMP corresponds to the current density fluctuation at the Cluster 3 spacecraft. For the

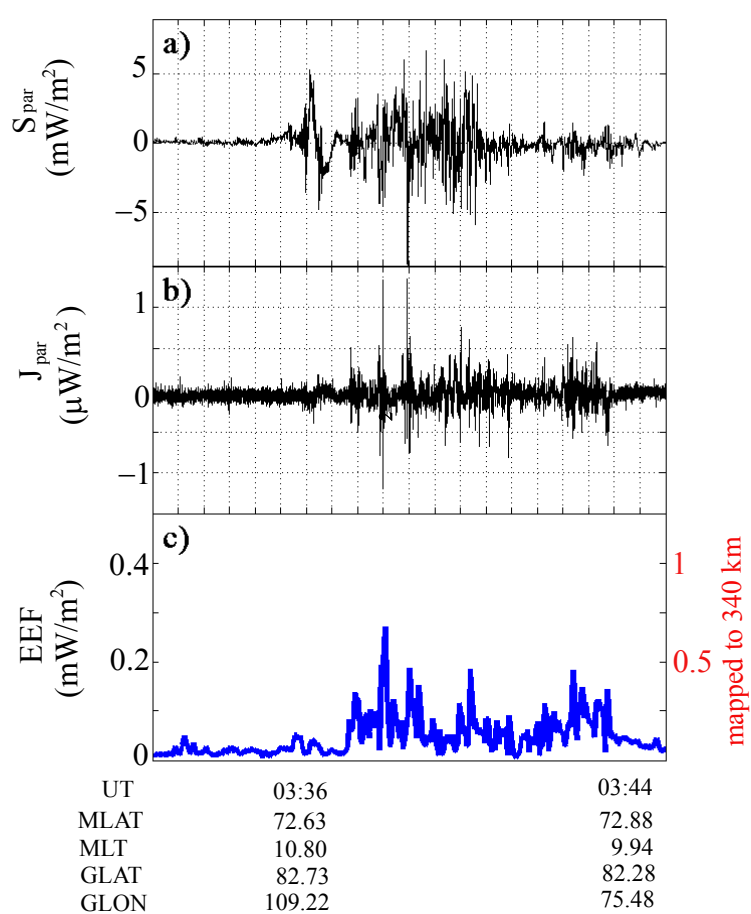

Figure 9. Cluster 3 on 17 July 2008: (a) parallel Poynting flux, (b) parallel current density, (c) electron energy fluxes, where blue colour indicates Earthward direction. Right axis shows EEF mapped to troposphere

magnetic field in the ionosphere $B_{\mathrm{i}} \approx 50 \mu \mathrm{T}$ and a mean magnetic field on Cluster $B_{\mathrm{cl}}$ of about $2 \mu \mathrm{T}$, the estimated current density fluctuation in the ionosphere is $5 \mu \mathrm{A} \mathrm{m}^{-2}$, which is very close to the average current density fluctuation computed from the CHAMP data. Since the cusp is a very dynamic area, we cannot expect that the exact same current peaks can be observed on the CHAMP some minutes later as at the Cluster, but similarity in current density fluctuations between these satellites, as well as proximity of their footpoints, indicate that the same bundle of FAC can be identified on both satellites. On the top of the CHAMP current density, normalized neutral density measured at CHAMP is plotted. Here, we see a local increase of the neutral density in the time around 03:47 UT, i.e. in the time when the CHAMP current is observed, though the current density peak is 1 minute delayed. This feature is not entirely unexpected and is a consequence of the fact that the plasma which produces the CHAMP current follows magnetic inclination, while neutral particle, heated at the bottom of the FAC bundle will rather expand radially upwards. The neutral density peak which occurred in the same time as CHAMP current intensification, is about $17 \%$ above the neutral density background. This peak is significant as is evidenced by mean and standard deviation of the air neutral density as reported in Table 1 . In Fig. 10b Joule heating is estimated for the $E$ layer. The average Joule heating fluctuation is $4 \mu \mathrm{Am}^{-2}$. The projected 
Table 1. Thermospheric upwelling in respect to the neutral background as a function of Poynting flux, Joule heating, EEF and CHAMP current density fluctuations for all three events.

\begin{tabular}{llll}
\hline Events & 24.6 .2009 & 17.7 .2008 & 09.06 .2008 \\
\hline Poynting flux $\left(\mathrm{mW} \mathrm{m}^{-2}\right)$ & 6.50 & 12.25 & 9.8 \\
Joule h. $\left(\mathrm{mW} \mathrm{m}^{-2}\right)$ & 2.88 & 1 & 1.18 \\
EEF $\left(\mathrm{mW} \mathrm{m}^{-2}\right)$ & 2.16 & 1 & 0.49 \\
FAC $\mu \mathrm{A} \mathrm{m}{ }^{-2}$ & 18 & 5.48 & 8.85 \\
Mean $($ density $)\left(\mathrm{kg} \mathrm{m}^{-3}\right)$ & $2.8 \times 10^{-12}$ & $1.5 \times 10^{-12}$ & $2.5 \times 10^{-12}$ \\
Std dev. (density) $\left(\mathrm{kg} \mathrm{m}^{-3}\right)$ & $3.0 \times 10^{-13}$ & $6.3 \times 10^{-13}$ & $4.9 \times 10^{-13}$ \\
Density peak $\left(\mathrm{kg} \mathrm{m}^{-3}\right)$ & $3.24 \times 10^{-12}$ & $2.54 \times 10^{-12}$ & $3.4 \times 10^{-12}$ \\
Thermo. Upp. (\%) & 20 & 17 & 11 \\
\hline
\end{tabular}
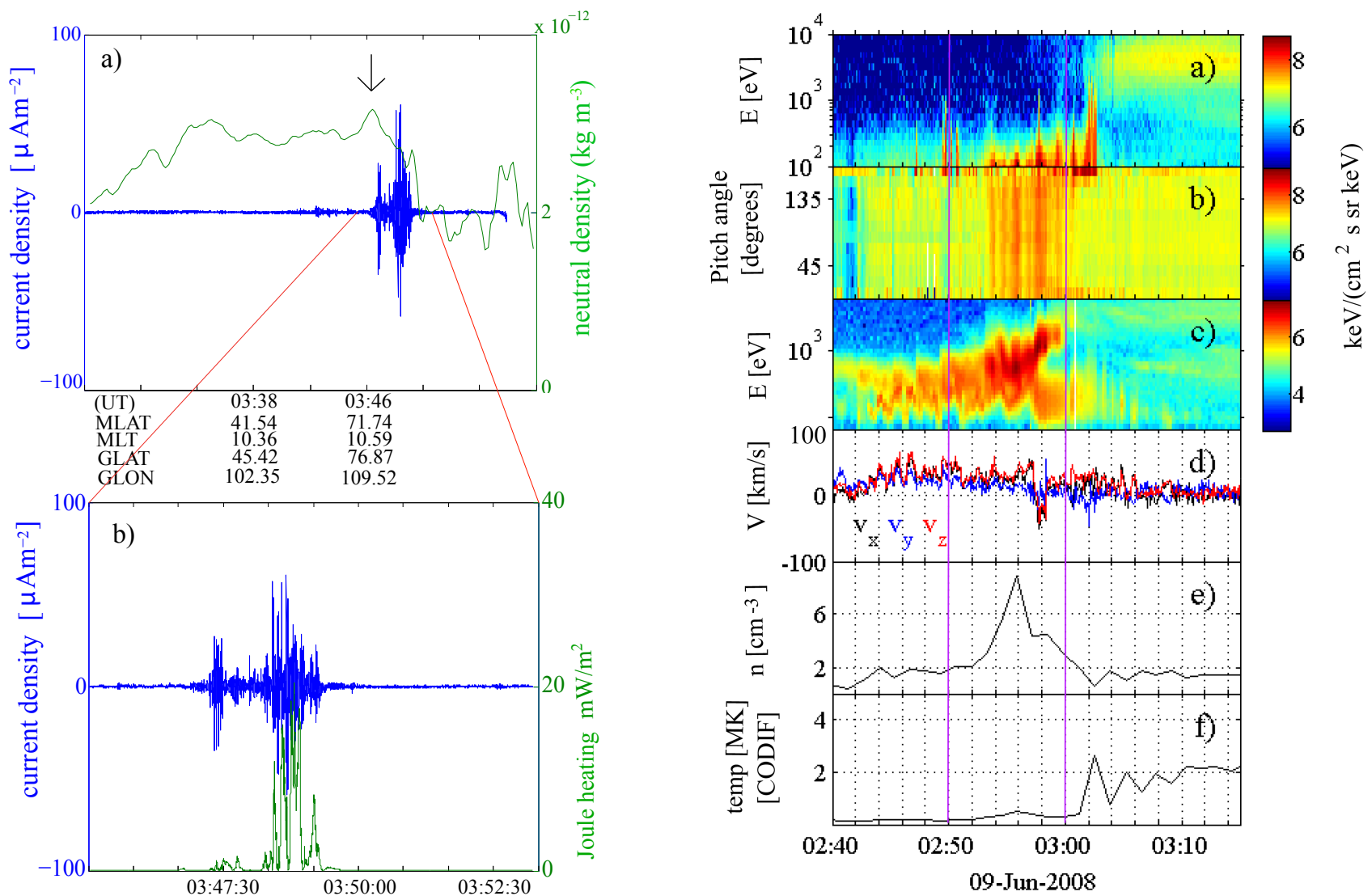

Figure 10. (a) CHAMP current and neutral density for 17 July 2008. (b) Estimated Joule heating for the $E$ layer. On the top of it is the CHAMP FAC density.

Poynting flux fluctuation from the Cluster 3 is $12.25 \mu \mathrm{A} \mathrm{m} \mathrm{m}^{-2}$ which is about 3 times higher than the average Joule heating fluctuations. We have also checked at the Cluster whether oxygen ions could have been detected. However, most of the ions detected on the CIS instrument were hydrogen which is originally coming from the magnetosphere and ultimately the solar wind.

Figure 11. Cluster 3 on 9 June 2008: (a) electron spectrogram, (b) pitch angle distribution of electrons, (c) ion spectrogram, (d) ion velocity in GSE, (e) ion density, (f) parallel (to mag. field) temperature. Two violet lines mark the cusp extension.

\subsection{June 2008 cusp event}

For this event, the OMNI database shows gaps in the time of conjunction for the solar IMF and solar wind dynamic pressure. However, considering that $D_{s t} \sim-10 \mathrm{nT}$ and low solar IMF before the conjunction, we can safely assume that this also is a quiet event. The $K_{\mathrm{p}}$ index was at about 2 in the period of several hours before this conjunction event, while the 


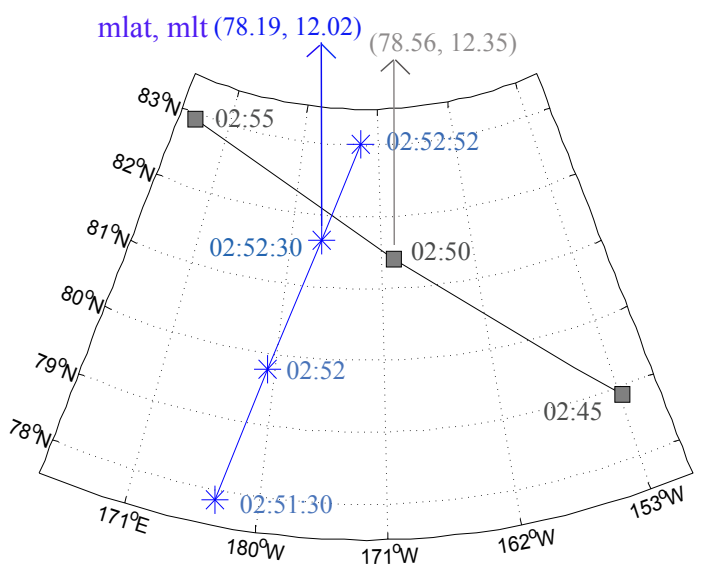

Figure 12. Satellite footprints in geographical coordinates for 9 June 2008: blue star is for CHAMP, grey square is for Cluster 3 . Colours of times in the plot correspond to the colours of satellite footprints. Arrows point to magnetic latitude and magnetic local time for satellites in conjunction.

AE index stayed less than $200 \mathrm{nT}$ in the same period. During the conjunction period, Cluster 3 was at $2.92 R_{\mathrm{E}}$. From Fig. 11, cusp precipitation can be identified between 02:50 and 03:00 UT. Cluster 3 and CHAMP satellite passages in geographic coordinates are plotted in Fig. 12. In the conjunction, footprints for the Cluster 3 are MLAT 78.56, MLT 12.35, and for CHAMP are MLAT 78.19, MLT 12.02. In Fig. 13a, intensification in the field-aligned Poynting flux can be seen. The average Earthward Poynting flux fluctuation during cusp passage between 02:50 and 03:00 UT is $0.49 \mathrm{~mW} \mathrm{~m}^{-2}$. The average current density fluctuation from the Cluster 3 data plotted in Fig. $13 \mathrm{~b}$ gives $0.2 \mu \mathrm{Am}^{-2}$ in the cusp interval. Its projection to the CHAMP altitude gives fluctuation of $5 \mu \mathrm{Am}^{-2}$. In Fig. 13c, Earthward EEF is plotted. The average fluctuation of the Earthward EEF is $0.01 \mathrm{~mW} \mathrm{~m}^{-2}$, while its extrapolated value to the thermosphere is only $0.2 \mathrm{~mW} \mathrm{~m}^{-2}$. The CHAMP current density fluctuation which is plotted in Fig. 14a is $8.85 \mu \mathrm{A} \mathrm{m}^{-2}$, which is slightly higher than estimated from the Cluster current density fluctuations.

In the period of intense CHAMP currents, there is also some thermospheric upwelling (see Fig. 14a), though it is smaller than the neutral density peak which can be observed 7 minutes earlier, but at a midlatitude location of $50^{\circ}$. This large neutral density enhancement must thus be of completely different origin than the one associated with the cusp observed at $80^{\circ}$ latitude. In fact, the thermospheric upwelling in the time of the CHAMP current intensification is only $11 \%$ higher than the above background. However, from Table 1 , the estimated mean of the air neutral density and its standard deviation show that the studied neutral density peak has a significant increase. In Fig. 14b a Joule heating for the $E$ layer together with a CHAMP current density is plotted. Average Joule heating fluctuation is $1.18 \mathrm{~mW} \mathrm{~m}^{-2}$.

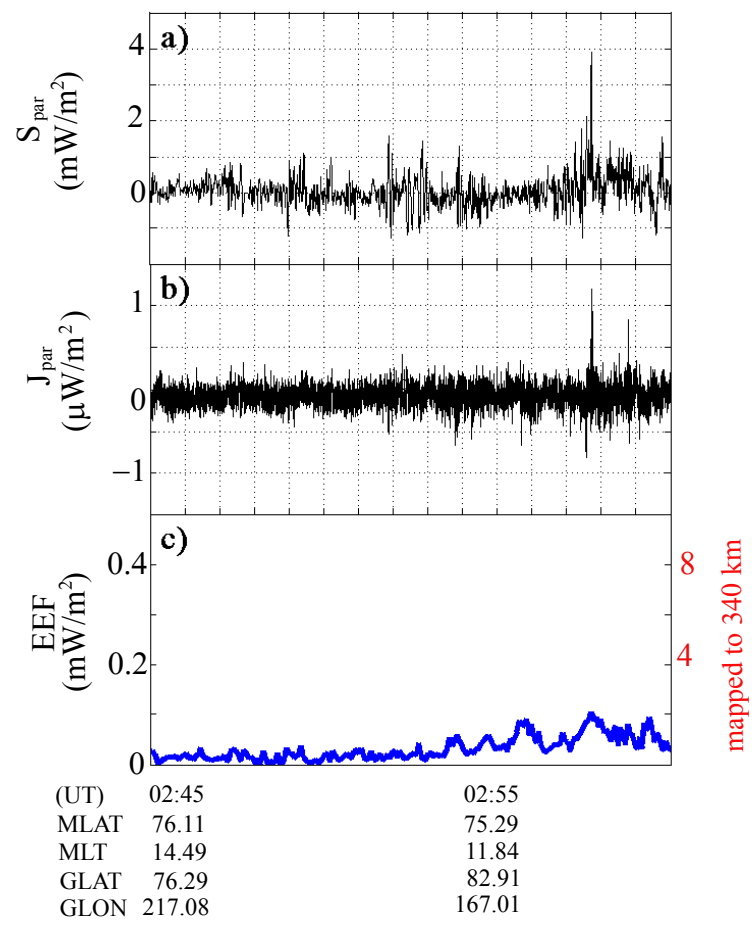

Figure 13. Cluster 3 on 9 June 2008: (a) parallel Poynting flux, (b) parallel current density, (c) electron energy fluxes, where blue colour indicates Earthward direction. Right axis shows EEF mapped to troposphere.

The projected Earthward Poynting flux average fluctuation is $9.8 \mathrm{~mW} \mathrm{~m}^{-2}$, which is 8 times higher than the average Joule heating fluctuations. As in the second case, no oxygen ions are detected at Cluster.

\subsection{Summary of the results}

In this paper we compare the projected particle energy and Poynting fluxes measured at about 2 Re by Cluster with estimates of integrated Joule heating and neutral density change from CHAMP. A summary is given in Table 1, where also the FAC density is shown. The event with the largest density change has also the largest Joule heating and EEF estimates.

In Table 1 we also report mean and standard deviation for the air density data for the time interval plotted in Figs. 4a, 10a and 14a. We can safely conclude that all density peaks which are also reported in Table 1 and which correspond to observed bundles of FAC are outside 1 standard deviation interval, which makes them distinguishable from other peaks in the data.

Our estimated Joule heating rates are smaller than the Poynting flux seen by Cluster by a factor between about 2.5 and 10. A similar discrepancy for a Cluster conjunction in the cusp was reported in Yordanova et al. (2007), where Joule heating was estimated using a different method and possible explanations were discussed. Compared to simulations by Crowley et al. (2010) and Deng et al. (2013), who aimed 

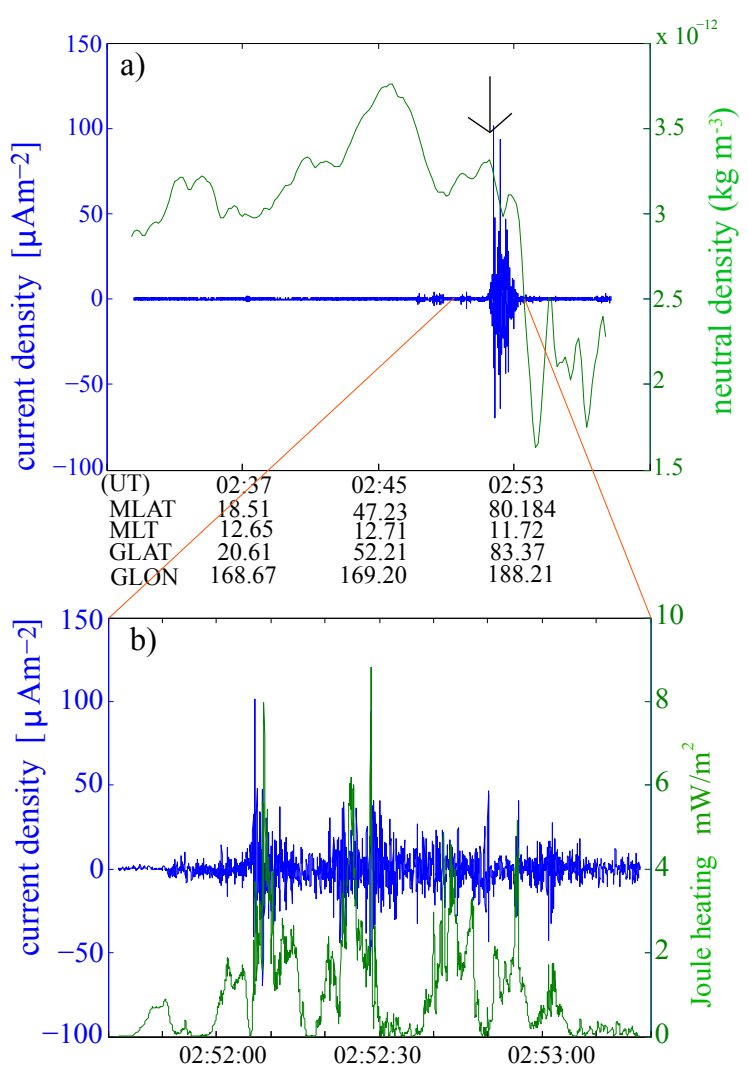

Figure 14. (a): CHAMP current and neutral density for 9 June 2008, (b): estimated Joule heating for the $E$ layer on 9 June 2008.

to model strong events, our Poynting flux values are smaller by a factor of 5-10, and the estimated Joule heating by 1-2 orders of magnitude smaller. The precipitating electron energy flux is relatively similar as in Deng et al. (2013). Thermospheric upwelling or at least density increases as observed in all cases, in spite of weak Poynting fluxes and Joule heating rates, points to a strong role of soft electron precipitation in the process. The Poynting flux and Joule heating rate represent total energy input into the ionosphere from above. It is also of significance for the effectiveness, how the total input gets distributed over the altitudes, but an investigation of this is beyond the scope of the presently available data. In the future height-resolving incoherent scatter radar data and simulations could be used to address this.

\section{Conclusions}

We have shown three cases of small-scale FAC bundles which stretch from the magnetosphere through the ionosphere inside the polar cusp. These FAC bundles are identified in the magnetosphere with the Cluster spacecraft, and in the ionosphere with the CHAMP spacecraft, which were in the conjunction during these events. In order to justify the conjunction approach, we have studied events under quiet and steady IMF and ionospheric conditions which lasted as such in a period of several hours prior to studied events. The CHAMP satellite identifies thermospheric upwellings for all three events. It has been pointed out already by Lühr et al. (2004) that the density enhancements accompanied by smallscale field-aligned currents in the cusp occur quite independently of magnetic activity. Also these events occurred under quiet geomagnetic and solar wind conditions. However, it was also pointed out by Liu et al. (2010) that only a few density enhancements occurred for IMF $\left|B_{z}\right|<5 \mathrm{nT}$. The first and the second event in this study are such examples.

Knipp et al. (2011) found that strong IMF $B_{y}$ preceded extreme Poynting flux depositions in the dayside thermosphere, which further could have been a source for cusp neutral density enhancements. Similar conclusions were also made by Crowley et al. (2010). The IMF $B_{y}$ was very low for each of the events we have studied, but nevertheless, thermospheric upwelling can be seen.

These events were chosen for their clear FAC signatures among all Cluster and CHAMP conjunctions for midaltitudes during the years 2008 and 2009. Other conjunctions revealed neither current flow on Cluster nor CHAMP, and notably also no density enhancements. There were no examples of current flows which were not accompanied by density enhancements. Also, there were no examples of density enhancements in the thermosphere, which were not accompanied by current flows.

We have estimated electron energy flux at Cluster. The quantitative analysis for all three events presented in Table 1 indicate that stronger soft electron precipitation is accompanied by stronger density enhancements in the thermosphere, which further strengthens the importance of soft electron precipitation in thermospheric upwellings. Further arguments that support this can be found in Clemmons et al. (2008) and Sadler et al. (2012). Clemmons et al. (2008) has explained density enhancements as a result of direct energy transfer from soft electrons to neutrals. On the other hand, Sadler et al. (2012) suggested that density enhancements could be explained as a combination of soft electrons which heat electrons in the thermosphere, and cause ion outflow.

For the case studies in this paper, we have checked densities and directions of oxygen ions measured from the CIS CODIF instrument on Cluster, because these ions are usually coming from the ionosphere. No oxygen ions in periods of cusp passages could be detected on 17 July 2008 and 9 June 2008. However, for the case of 24 June 2009, when Clusters 3 and 4 were less than or at about $2 R_{\mathrm{E}}$ from the Earth and when solar wind dynamic pressure was high (about $8 \mathrm{nPa}$ ), we could detect oxygen density as high as $4 \mathrm{~cm}^{-3}$ with velocities up to $20 \mathrm{~km} \mathrm{~s}^{-1}$ antiparallel to the magnetic field. These velocities correspond to results from Sadler et al. (2012). This may be an indication that thermosphere upwelling (neutral density increase) is associated also with ion outflow. 
Both Joule heating and soft electron precipitation provide significant energy input into the ionosphere with the potential to trigger thermosphere upwelling.

Rentz and Lühr (2008) had emphasized the role of Joule heating, while Clemmons et al. (2008) as well as Sadler et al. (2012) discarded it. They rather advocated soft particle precipitation as the cause of upwelling, which would directly heat the neutral atmosphere, and, according to Sadler et al. (2012), also trigger ion upflow with an additional drag effect on the neutrals. Deng et al. (2013) found by simulation only a small effect from soft precipitation alone. However, the electron density increase would amplify Joule heating at high altitudes. Consequently, they argued for a combination of Joule heating and precipitation which is needed to trigger upwelling. Also Kervalishvili and Lühr (2013), using CHAMP and DMSP data, argued for a combination of causes. Overall, also our data seem to support that a combination of Joule heating and precipitation is the cause of upwelling, but in weak events the magnitude of Joule heating becomes comparatively smaller.

For our three events we have quantitatively estimated the height-integrated Joule heating rates from CHAMP's magnetic field data and from modelled conductances. The rates are several $\mathrm{mW} \mathrm{m}^{-2}$, where most would be deposited in the $E$ and lower $F$ region. Further, Joule heating rate is roughly 1 order of magnitude smaller than needed to explain strong upwelling events. For those, a combination of Joule heating and soft particle energy flux was important, according to simulations (Crowley et al. (1996), Clemmons et al. (2008), Deng et al. (2013), etc.). In this study, Cluster has observed soft particle energy flux at about $2 \mathrm{Re}$. The mapped fluxes were a few $\mathrm{mW} \mathrm{m}^{-2}$, roughly the same magnitude as used by Deng et al. (2013). We note that, for the weak events studied here, the ratio of Joule heating to mapped particle energy flux was roughly 1 , while in the simulated strong events this ratio was about 32 . Therefore, weaker events could be characterized by a higher proportion of particle energy flux.

In summary, using Cluster and CHAMP data we have estimated the energy input by Joule heating and compared it with the net downward electron energy and Poynting flux. In three studied events, which all have rather quiet solar wind and ionospheric conditions, electron energy flux seems to give the main contribution to the thermospheric density enhancements.

Acknowledgements. We would like to thank Hermann Lühr for fruitful scientific discussions and for the provision of CHAMP data. The CHAMP mission was sponsored by the Space Agency of the German Aerospace Centre (DLR) through funds of the Federal Ministry of Economics and Technology. T. Živković and H. Opgenoorth would like to acknowledge the European Union Framework 7 Programme and the ECLAT project. L. Palin and S. Buchert acknowledge support from the Swedish National Space Board. Also, we acknowledge the ESA Cluster Archive and thank Eelco Doornbos for making a great web site from which we have downloaded CHAMP neutral density data. We would also like to thank Andris Vaivads and Yuri Khotyaintsev for valuable discussions.

The topical editor L. Blomberg thanks two anonymous referees for help in evaluating this paper.

\section{References}

Balogh, A., Carr, C. M., Acuña, M. H., Dunlop, M. W., Beek, T. J., Brown, P., Fornacon, K.-H., Georgescu, E., Glassmeier, K.H., Harris, J., Musmann, G., Oddy, T., and Schwingenschuh, K.: The Cluster Magnetic Field Investigation: overview of in-flight performance and initial results, Ann. Geophys., 19, 1207-1217, doi:10.5194/angeo-19-1207-2001, 2001.

Baumjohann W.: Ionospheric and field-aligned current systems in the auroral zone: a concise review, Adv. Space Res., 2, 55-62, doi:10.1016/0273-1177(82)90363-5, 1982.

Birkeland, K.: The Norwegian Aurora Polaris Expedition 19021903, 1, 319-801, H. Aschehoug and Co., Christiania (Oslo), 1913.

Chaston, C. C., Peticolas, L. M., Carlson, C. W., McFadden, J. P., Mozer, F., Wilber, M., Parks, G. K., Hull, A., Ergun, R. E., Strangeway, R. J., André, M., Khotyaintsev, Y., Goldstein, M. L., Acuna, M., Lund, E. J., Reme, H., Dandouras, I., Fazakerley, A. N., and Balogh, A.: Energy deposition by Alfven waves into the dayside auroral oval: Cluster and FAST observations, J. Geophys. Res., 110, A02211, doi:10.1029/2004JA010483, 2005.

Carlson, H. C., Spain, T., Aruliah, A., and Skjaeveland, A.: Firstprinciples physics of cusp/polar cap thermospheric disturbances, Geophys. Res. Lett., 39, L19103, doi:10.1029/2012GL053034, 2012.

Crowley, G., Knipp, D. J., Drake, K. A., Lei, J., Sutton, E., and Lühr, H.: Cellular structures in the high latitude thermosphere, J. Geophys. Res., 101, 211-223, 1996.

Crowley, G., Knipp, D. J., Drake, K. A., Lei, J., Sutton, E., Lühr, H.: Thermospheric density enhancements in the dayside cusp region during strong $B_{y}$ conditions, Geophys. Res. Lett., 37, L07110, doi:10.1029/2009GL042143, 2010.

Clemmons, J. H., Hecht, J. H., Salem, D. R., Strickland, D. J., Thermospheric density in the Earth's magnetic cusp as observed by the Streak mission, Geophys. Res. Lett., 35, L24103, doi:10.1029/2008GL035972, 2008.

Dahlgren, H., Gustavsson, B., Lanchester, Dahlgren, H., Gustavsson, B., Lanchester, B. S., Ivchenko, N., Brändström, U., Whiter, D. K., Sergienko, T., Sandahl, I., and Marklund, G.: Energy and flux variations across thin auroral arcs, Ann. Geophys., 29, 16991712, doi:10.5194/angeo-29-1699-2011, 2011.

Deng, Y., Fuller-Rowell, T. J., Ridley, A. J., Knipp, D., and Lopez, R. E.: Theoretical study: Influence of different energy sources on the cusp neutral density enchancements, J. Geophys. Res., 118, 2340-2349, doi:10.1002/jgra.50197, 2013.

Doornbos, E., van den IJssel, J., Lühr, H., Förster, M., and Koppenwallner, G.: Neutral density and crosswind determination from arbitrarily oriented multiaxis accelerometers on Satellites, J. Spacecraft Rockets, 47, 580-589, 2010.

Gustafsson, G., André, M., Carozzi, T., Eriksson, A. I., Fälthammar, C.-G., Grard, R., Holmgren, G., Holtet, J. A., Ivchenko, N., Karlsson, T., Khotyaintsev, Y., Klimov, S., Laakso, H., Lindqvist, P.-A., Lybekk, B., Marklund, G., Mozer, F., Mursula, K., Peder- 
sen, A., Popielawska, B., Savin, S., Stasiewicz, K., Tanskanen, P., Vaivads, A., and Wahlund, J.-E.: First results of electric field and density observations by Cluster EFW based on initial months of operation, Ann. Geophys., 19, 1219-1240, doi:10.5194/angeo19-1219-2001, 2001.

Hedin, A. E.: Extension of the MSIS thermosphere model into the middle and lower atmosphere, J. Geophys. Res., 96, 1159-1172, 1991.

Johnstone, A. D., Alsop, C., Burge, S., Carter, P. J., Coates, A. J., Coker, A. J., Fazakerley, A. N., Grande, M., Gowen, R. A, Gurgiolo, C., Hancock, B. K, Narheim, B., Preece, A, Sheather, P. H, Winningham, J. D, Woodliffe, R. D.:, PEACE: A Plasma Electron and Current Experiment, Space Sci. Rev., 79, 351-398, 1997.

Kelly, M. C.: The Earth's Ionosphere: Plasma Physics and Electrodynamics, Elsevier, ISBN-13: 9780323148054, 2012.

Kervalishvili, G. N. and Lühr, H.: The relationship of thermospheric density anomaly with electron temperature, small-scale FAC, and ion up-flow in the cusp region, as observed by CHAMP and DMSP satellites, Ann. Geophys., 31, 541-554, doi:10.5194/angeo-31-541-2013, 2013.

Knipp, D., Eriksson, S., Kilcommons, L., Crowley, G., Lei, J., Hairston, M., and Drake, K.: Extreme Poynting flux in the dayside thermosphere. Examples and statistics, Geophys. Res. Lett., 38, L16102, doi:10.1029/2011GL048302, 2011.

Li, W., Knipp, D., Lei, J., and Raeder, J.: The relation between dayside local Poynting flux enhancement and cusp reconnection, J. Geophys. Res., 116, A08301, doi:10.1029/2011JA016566, 2011.

Liu, R., Lühr, H., Doornbos, E., and Ma, S.-Y.: Thermospheric mass density variations during geomagnetic storms and a prediction model based on the merging electric field, Ann. Geophys., 28, 1633-1645, doi:10.5194/angeo-28-1633-2010, 2010.

Liu, R., Lühr, H., and Ma, S.-Y.: Storm-time related mass density anomalies in the polar cap as observed by CHAMP, Ann. Geophys., 28, 165-180, doi:10.5194/angeo-28-165-2010, 2010.

Lühr, H., Warnecke, J., Zanetti, L. J., Lindqvist, P. A., and Hughes, T. J.: Fine structure of field-aligned current sheets deduced from spacecraft and ground based observations: Initial FREJA results, Geophys. Res. Lett., 21, 1883-1886, doi:10.1029/94GL01278, 1994.

Lühr, H., Rother, M., Köhler, W., Ritter, P., and Grunwaldt, L.: Thermospheric up-welling in the cusp region: Evidence from CHAMP observations, Geophys. Res. Lett, 31, L06805, doi:10.1029/2003GL019314, 2004.

Neubert, T. and Christiansen, F.: Small-scale, field-aligned currents at the top-side ionosphere, Geophys. Res. Lett., 30, NO.19, doi:10.1029/2003GL017808, 2003.

Picone, J. M., Hedin, A. E., Drob, D. B., and Aikin, A. C.: NRLMSISE-00 empirical model of the atmosphere: Statistical comparison and scientific issues, J. Geophys. Res., 107, 1468, doi:10.1029/2002JA009430, 2002.

Pitout, F., Escoubet, C. P., Taylor, M. G. G. T., Berchem, J., and Walsh, A. P.: Overlapping ion structures in the mid-altitude cusp under northward IMF: signature of dual lobe reconnection?, Ann. Geophys., 30, 489-501, doi:10.5194/angeo-30-489-2012, 2012.

Rème, H., Aoustin, C., Bosqued, J. M., Dandouras, I., Lavraud, B., Sauvaud, J. A., Barthe, A., Bouyssou, J., Camus, Th., Coeur-Joly, O., Cros, A., Cuvilo, J., Ducay, F., Garbarowitz, Y., Medale, J. L., Penou, E., Perrier, H., Romefort, D., Rouzaud, J., Vallat, C.,
Alcaydé, D., Jacquey, C., Mazelle, C., d’Uston, C., Möbius, E., Kistler, L. M., Crocker, K., Granoff, M., Mouikis, C., Popecki, M., Vosbury, M., Klecker, B., Hovestadt, D., Kucharek, H., Kuenneth, E., Paschmann, G., Scholer, M., Sckopke, N., Seidenschwang, E., Carlson, C. W., Curtis, D. W., Ingraham, C., Lin, R. P., McFadden, J. P., Parks, G. K., Phan, T., Formisano, V., Amata, E., Bavassano-Cattaneo, M. B., Baldetti, P., Bruno, R., Chionchio, G., Di Lellis, A., Marcucci, M. F., Pallocchia, G., Korth, A., Daly, P. W., Graeve, B., Rosenbauer, H., Vasyliunas, V., McCarthy, M., Wilber, M., Eliasson, L., Lundin, R., Olsen, S., Shelley, E. G., Fuselier, S., Ghielmetti, A. G., Lennartsson, W., Escoubet, C. P., Balsiger, H., Friedel, R., Cao, J.-B., Kovrazhkin, R. A., Papamastorakis, I., Pellat, R., Scudder, J., and Sonnerup, B.: First multispacecraft ion measurements in and near the Earth's magnetosphere with the identical Cluster ion spectrometry (CIS) experiment, Ann. Geophys., 19, 1303-1354, doi:10.5194/angeo19-1303-2001, 2001.

Rentz, S. and Lühr, H.: Climatology of the cusp-related thermospheric mass density anomaly, as derived from CHAMP observations, Ann. Geophys., 26, 2807-2823, doi:10.5194/angeo-262807-2008, 2008.

Sadler, F. B., M. Lessard, E. Lund, A. Otto, and Lühr, H.: Auroral precipitation/ion upwelling as a driver of neutral density enchancements in the cusp, J. A. Sol.-Terr. Phy., 87-88, 82-90, 2012.

Schlegel, K., Lühr, H., St.-Maurice, J.-P., Crowley, G., and Hackert, C.: Thermospheric density structures over the polar regions observed with CHAMP, Ann. Geophys., 23, 1659-1672, doi:10.5194/angeo-23-1659-2005, 2005.

Schunk, R. W. and A. Nagy, Ionospheres, Cambridge University Press, New York, 2004.

Sugiura, M.: A fundamental magnetosphere-ionosphere coupling mode involving field-aligned currents as deduced from DE-2 observations, Geophys. Res. Lett., 1, 877-880, 1984.

Tsyganenko, N. A. and Stern, D. P. : Modeling the global magnetic field of the large-scale Birkeland current systems, J. Geophys. Res., 101, 27187-27198, 1996.

Tsyganenko, N. A.: Magnetic field and electric currents in the vicinity of polar cusps as inferred from Polar and Cluster data, Ann. Geophys., 27, 1573-1582, doi:10.5194/angeo-27-15732009, 2009.

Yordanova, E., Sundkvist, D., Buchert, S. C., André, M., Ogawa, Y., Morooka, M., Margithu, O., Amm, O., and Fazakerley, A. N.: Energy input from the exterior cusp into the ionosphere: Correlated ground based and satellite observations. Geophys. Res. Lett., 34, L04102, doi:10.1029/2006GL028617, 2007.

Wahlund, J.-E., Opgenoorth, H. J., Häggström, I., Winser, K. J., and Jones, G. O. L.: EISCAT observations of topside ionospheric ion outflows during auroral activity: Revisited, J. Geophys. Res., 97, 3019-3037, doi:10.1029/91JA02438, 1992.

Wang, H., Lühr, H. and Ma, S. Y.: Solar zenith angle and merging electric field control of field-aligned currents: A statistical study of the Southern Hemisphere, J. Geophys. Res., 110, A03306, doi:10.1029/2004JA010530, 2005.

Watermann, J., Christiansen, F., Popov, V., Stauning, P., and Rasmussen, O.: Field-aligned currents inferred from low-altitude Earth-orbiting satellites and ionospheric currents inferred from ground-based magnetometers - do they render consistent results? in: First CHAMP Mission Results for Gravity, Magnetic 
and Atmospheric Studies, edited by: Reigber, C., Lühr, H. and Schwintzer, P., Springer-Verlag Heidelberg, Germany, 2003.

Watermann, J., Stauning, P., Lühr, H., Newell, P. T., Christiansen, F., and Schlegel, K.: Are small-scale field-aligned currents and magnetospheath-like particle precipitation signatures of the same low-altitude cusp? Adv. Space Res., 43, 41-46, 2008.
Whitteker, J. H.: The transient response of the topside ionosphere to precipitation, Planet. Space Sci., 25, 773-386, 1977. 